\title{
Rhamnolipids: The Next Generation Multifunctional Biomolecules for Applications Against Meloidogyne incognita in Tomato Plants
}

\author{
Thomas Thomidis ${ }^{1}$, Ioanna Prodromou ${ }^{1} \&$ Argyrios Farmakis $^{1}$ \\ ${ }^{1}$ International Hellenic University, Department of Agriculture, Campus of Sindos, Thessaloniki, Greece \\ Correspondence: Thomas Thomidis, International Hellenic University, Department of Agriculture, Campus of \\ Sindos, 57400, Thessaloniki, Greece. E-mail: thomidis@cp.teithe.gr; thomi-1@otenet.gr
}

Received: March 17, 2021

Accepted: July 5, $2021 \quad$ Online Published: August 15, 2021

doi:10.5539/jas.v13n9p93

URL: https://doi.org/10.5539/jas.v13n9p93

\begin{abstract}
Plant parasitic nematodes are a global threat to tomato production due to severe damages they cause to roots. The main aim of this study was to investigate the effect of rhamnolipids to control the nematode Meloidogyne incognitain tomato plants. It was applied as soil drench in soil naturally infested with the nematodes. The results showed that the number of small size galls was statistically less in the plants treated with fluopyram than untreated control or rhamnolipids. Plants treated with rhamnolipids had significantly less number of small size galls than untreated control. The number of medium size galls was significant less in plants treated with fluopyram than untreated control. Plants treated with rhamnolipids did not show any difference in the number of medium size galls than untreated control or fluopyram. No significant difference was found among all treatments in the number of big size galls although the plants treated with rhamnolipids or fluopyram had the tendency to show less number. Generally, this study demonstrated the potential of rhamnolipids (biological) to control $M$. incognita in tomato cultivars.
\end{abstract}

Keywords: control, Meloidogyne incognita, nematodes, Solanum lycopersicum

\section{Introduction}

Tomato (Solanum lycopersicum L.), consists of an important crop for Greece and worldwide. In 2018, the world production of tomatoes was $182,258,016$ tones, within a harvesting area of 4,762,129 million ha globally (FAOSTAT, 2018). Plant-parasitic nematodes are of the most important problem for the tomato cultivation, with the root-knot nematodes of the genus Meloidogyne (M. artiella, M. incognita and M. javanica) to be the most important (Seid et al., 2015). Nematode's infestation reduces functionality of roots leads to water stress and nutrient deficiency, which in turn lead to poor plant growth and reduce yield. Also the nematode's parasitism follows subsequent infestation by secondary pathogens, such as fungi and bacteria as a result either through mechanical damage, but also on a genetic basis (Zhang et al., 2021). Nematicides are largely prohibited in many countries and horticultural measures such as resistant or tolerant plant varieties (Quénéhervé, 2009) if available, often fail to solve the problem completely. Thus, the development of new, effective and environmentally compatible control measures is necessary.

Biosurfactants (BSFs) arepromising example for such an alternative in crop protection as a natural weapon to antagonize plant pathogens. These secondary metabolites, produced by various ubiquitous microorganisms, show an imposing efficiency against numerous economically relevant pathogens in agriculture. Rhamnolipids is synthetic surfactants, produced by Pseudomonas aerigusta (Kaskatepe \& Yildi, 2016) and they are of the most studied biosurfactants due to the potential applications in a wide variety of industries. Rhamnolipids have been demonstrated to control plant nematodes (Bredenbruch et al., 2017).

The main aim of this study was to investigate the effect of the biological product Rhapynal $(70 \%$ rhamnolipids, Biotensidon $\mathrm{GmbH}$, Karlsruhe, Germany) to control the nematode M. incognita in tomato plants

\section{Methods}

All the experiments were conducted in the experimental glasshouse of International Hellenic University, Campus of Sindos, located in Thessaloniki, Northern Greece, in August 2018 and againin August 2019. 


\subsection{Soil Analysis}

The soil was sandy loam with a $\mathrm{pH} 7.4$, high salinity ( $5.3 \mathrm{mS}$ conductivity), medium organic matter ( $2 \%)$, and low $\mathrm{CaCO}_{3}(0.5 \%)$. The soil was naturally infested with nematode identified as $M$. incognita. Soil was assayed for plant-parasitic nematodes $M$. incognita 60 days after planting. Cores $(2.5 \times 15 \mathrm{~cm})$ of soil were collected from the center rows of each treatment and mixed thoroughly. Nematodes from soil samples were extracted using a Baermann funnel technique. The recovered nematode suspension was expressed as J2/100 g soil.

\subsection{Testing Rhamnolipids Against Meloidogyne incognita}

Six-week-old tomato seedlings were transplanted in 3 rows, at a distance of $0.50 \mathrm{~m}$ between plants and $1 \mathrm{~m}$ between rows. Spray applications were applied against pests (by using Vertimec 1.8 EC, $1.8 \%$ abamectin, Syngenta Hellas) and diseases (by using Ortiva Top 20/12.5 SC, 20\% azoxystrobin $+12.5 \%$ Difenoconazole, Syngenta Hellas) of tomato and irrigated according to the water requirements of the crop. There were three treatments: a) soil drench of the plants with solution of Rhapynal at rates of $7 \mathrm{~g} / \mathrm{m}^{2}$, b) soil drench of the plants with solution of Velum Prime (reference product) (40\% fluopyram, Bayer Hellas, Marousi Athens, Greece) at rates of $0.0625 \mathrm{ml} / \mathrm{m}^{2}$ (recommended by manufacturer), and c) soil drench of the plants with water. Rhapynal was firstly applied immediately after transplanting andrepeated 4 timesevery 14 days. Applications with Velum Prime was conductedimmediately after transplanting and repeated once 25 days later. The tomato plants were uprooted 90 days after transplanting and the roots were washed to remove the soil. Data were collecting by recording the number of galls. There were three categories: small size galls with a diameter $<3 \mathrm{~mm}$, medium size galls with a diameter 3-6 $\mathrm{mm}$, and big size galls with a diameter $>6 \mathrm{~mm}$. In addition the total weight of the above-ground parts of the tomato plants were weighted.

\subsection{Experimental Design and Statistical Analysis}

The experimental design was completely randomized block. There were 3 replicates, each with four plants. To test significant differences between treatments (effect of temperatures and leaf wetness on the conidia germination), the General Linear Models procedure of SPSS was applied (SPSS Grad Pack 23, SPSS Inc., Chicago, Illinois). Significant differences between treatments were tested by Duncan's Multiple Range Test at P $=0.05$.

\section{Results and Discussion}

In 2018, the number of small size galls was statistically less (24.9) in the plants treated with fluopyram than untreated control (174.2) or rhamnolipids (53.3) (Table 1). Plants treated with rhamnolipids had significantly less number of small size galls than untreated control. The number of medium size galls was significant less in plants treated with fluopyram (1.7) than untreated control (14.2). Plants treated with rhamnolipids (6.2) did not show any difference in the number of medium size galls than untreated control or fluopyram. No significant difference was found among all treatments in the number of big size galls although the plants treated with rhamnolipids (3.1) or fluopyram 1.2) had the tendency to show less number (number of big size galls in untreated control 6.3). Similarly, the total weight of above-ground parts of the plants did not show any statistical difference among plants although the plants treated with rhamnolipids $(6.0 \mathrm{~g})$ or fluopyram $(7.9 \mathrm{~g})$ had a tendency to show increased weight (Table $1)$.

Table 1. Nematicidal effect of rhamnolipids against Meloidogyne incognita of tomato plants

\begin{tabular}{|c|c|c|c|c|c|}
\hline Treatments & Small Size Galls & Medium Size Galls & Big Size Galls & Weight of the Above-Ground Parts (kg) & J2/100 g Dry Soil \\
\hline \multicolumn{6}{|l|}{ Year 2018} \\
\hline Control & $174.2 \mathrm{a}^{\mathrm{z}}$ & $14.2 \mathrm{a}$ & 6.3 & $5.8 \quad \mathrm{a}$ & 271 a \\
\hline Rhamnolipids & $53.3 \mathrm{~b}$ & $6.2 \mathrm{ab}$ & $3.1 \mathrm{c}$ & $6.0 \quad \mathrm{a}$ & $117 \mathrm{~b}$ \\
\hline \multirow[t]{2}{*}{ Fluopyram } & $24.9 \mathrm{c}$ & $1.7 \mathrm{~b}$ & $1.2 \mathrm{c}$ & $7.9 \quad \mathrm{a}$ & 68 \\
\hline & $\mathrm{SE}=27.4$ & $\mathrm{SE}=3.1$ & $\mathrm{SE}=2.1$ & $\mathrm{SE}=1.03$ & $\mathrm{SE}=36$ \\
\hline \multicolumn{6}{|l|}{ Year 2019} \\
\hline Control & $13.1 \mathrm{a}^{\mathrm{z}}$ & $2.19 \mathrm{a}$ & 0.95 a & $3.25 \mathrm{a}$ & 138 a \\
\hline Rhamnolipids & 5.0 & $0.32 \mathrm{a}$ & 0.0 & $4.44 \mathrm{ab}$ & 42 \\
\hline \multirow[t]{2}{*}{ Fluopyram } & 0.9 & $1.0 \quad \mathrm{a}$ & 0.0 & $7.89 \mathrm{~b}$ & 31 \\
\hline & $\mathrm{SE}=2.51$ & $\mathrm{SE}=0.51$ & $\mathrm{SE}=0.23$ & $\mathrm{SE}=1.05$ & $\mathrm{SE}=17$ \\
\hline
\end{tabular}

Note. ${ }^{\mathrm{z}}$ Values in the same column followed by different letters were significantly different at $\mathrm{P}=0.05$ according to the Duncan's Multiple Range Test. 
In 2019, plants treated with fluopyram (0.9) showed significant less number of small size galls than untreated control (13.1) (Table 1). No significant difference was found in the number of small size galls between plants treated with rhamnolipids (5.0) and untreated control or plants treated with fluopyram. No significant difference was found among all treatments in the number of medium size galls although the plants treated with rhamnolipids (0.32) or fluopyram (1.0) had the tendency to show less number (number of big size galls in untreated control 6.3). No big size galls was found in plants treated with rhamnolipids or fluopyram. In contrast a number of 0.95 big size galls were found in untreated control plants. Finally, no significant difference was found in the total weight of the above-ground parts between plants treated with rhamnolipids $(4.44 \mathrm{~g})$ and untreated control $(3.25 \mathrm{~g})$. Plants treated with fluopyram had similar total weight of the above-ground parts with rhamnolipids but significantly higher than untreated control (Table 1).

In both years, the populations of nematodes were significant reduced in the soil treated with rhamnolipids (117 and $42 \mathrm{~J} 2 / 100 \mathrm{~g}$ dry soil in 2018 and 2019 respectively) and fluopyram (68 and 31 J2/100 g dry soil in 2018 and 2019 respectively) in comparison to untreated control (271 and $138 \mathrm{~J} 2 / 100 \mathrm{~g}$ dry soil in 2018 and 2019 respectively) (Table 1). The population of $M$. incognita was significant higher in the soil treated with rhamnolipids than that treated with fluopyram in 2018 , while there was no significant difference in the population of nematodes between rhamnolipids and fluopyram in 2019.

The above results demonstrated the potential of fluopyram (chemical) and rhamnolipids (biological) to control $M$. incognita in tomato cultivars. According to the Dahlin et al. (2019), the nematicide fluopyram controlled $M$. incognita as shown by the evaluation of the soil population, the tomato root gall formation and number of egg masses developed per plant. However, there is the limitation that nematicide fluopyram can only be applied pre-plant and up to 6 weeks post planting as it showed moderate mobility in soil, and the residual level in cucumber fruits increased up to 20 days at an application dose of $0.056 \mathrm{mg} / \mathrm{kg}$ (Chawla et al., 2018). In contrast to the nematicide fluopyram, rhamnolipids is a biological product without residuals which can be used even at the harvest period. Previous studies reported that the microbial biosurfactant having a rhamnolipid, and providing the microbial biosurfactant to one or more pests in an amount such that the one or more pests are controlled, wherein the pests are nematodes (Bredenbruch et al., 2017). Bredenbruch et al. (2016) found that plant infection by the cyst nematode $H$. schachtii and the root-knot nematode $M$. incognita was inhibited at rhamnolipids' concentrations far below the ecotoxicological level by mainly reinforcing plant defense already in advance to a pathogen attack thus enabling the plant to react more appropriate. Even in the case that the parasite is able to overcome this first hurdle, there is strong evidence that rhamnolipids modify the quality of the plant as a host. In this respect, galls of $M$. incognita are reduced in size and most importantly they cause a drop in the reproduction of both plant parasitic nematodes.

\section{Conclusion}

This study demonstrated the potential of rhamnolipids (biological) to control M. incognita in tomato cultivars. This is an environmentally friendly product which could be also used in biological production system.

\section{References}

Bredenbruch, S., Matsuoka, K., Gurung, R., Mellage, K., Grundler, F., \& Schleke, S. (2016). Biosurfactants control plant-parasitic nematodes. Synthetic and natural compounds for nematode control, $32^{\text {nd }}$ ESN Symposium, Branga, Portugal.

Bredenbruch, S., Mueller, J., Grundler, W. M. F., \& Schleker, S. (2017). PT-NMI-22 Microbial rhamnolipids mediate control of plant parasitic nematodes through several mechanisms. International Symposium Microbe-assisted Crop Production-Opportunities, Challenges \& Needs, December 4-7, 2017, Schloss Schönbrunn, Orangerie, Vienna, Austria.

Chawla, S., Patel, D. J., Patel, S. H., Kalasariya, R. L., \& Shah, P. G. (2018). Behaviour and risk assessment of fluopyram and its metabolite in cucumber (Cucumis sativus) fruit and in soil. Environmental Science and Pollution Research, 25, 11626-11634. https://doi.org/10.1007/s11356-018-1439-y

Dahlin, P., Eder, R., Consoli, E., Krauss, J., \& Kiewnick, S. (2019). Integrated control of Meloidogyne incognita in tomatoes using fluopyram and Purpureocillium lilacinum strain 251. Crop Protection, 124, 104874. https://doi.org/10.1016/j.cropro.2019.104874

FAOSTAT. (2018). Retrieved from http://www.fao.org/faostat/en/\#data/QC/visualize

Kaskatepe, B., \& Yildiz, S. (2016). Rhamnolipid biosurfactants produced by Pseudomonas species. Brazilian Archives of Biology and Technology, 59, e16160786. https://doi.org/10.1590/1678-4324-2016160786 
Quénéhervé, P. (2009). Integrated management of banana nematodes. In A. Ciancio, \& K. G. Mukerji (Eds.), Integrated management of fruit crops and forest nematodes (pp. 3-61). Springer Science+Business Media B.V. https://doi.org/10.1007/978-1-4020-9858-1_1

Seid, A., Fininsa, C., Mekete, T., Decraemer, W., \& Wesemael, W. M. L. (2015). Tomato (Solanum lycopersicum) and root-knot nematodes (Meloidogyne spp.)—A century-old battle. Nematology, 17, 995-1009. https://doi.org/10.1163/15685411-00002935

Zhang Y., Li, S., Li, H., Wang, R., Zhang, K. Q., \& Xu, J. (2021). Fungi-nematode interactions: Diversity, ecology, and biocontrol prospects in agriculture. Journal of Fungi, 6, 206. https://doi.org/10.3390/ jof6040206

\section{Copyrights}

Copyright for this article is retained by the author(s), with first publication rights granted to the journal.

This is an open-access article distributed under the terms and conditions of the Creative Commons Attribution license (http://creativecommons.org/licenses/by/4.0/). 